\title{
Learning through urban labour pools: Collected worker experiences and innovation in services
}

Sverre Herstad. Department of Sociology and Human Geography, University of Oslo. Mail to: s.j.herstad@sgeo.uio.no

Marte C.W Solheim. Centre for innovation research, UiS Business School, University of Stavanger.

Marit Engen. Service Research Center, Karlstad University

Accepted for publication in Environment and Planning A (2019)

\begin{abstract}
Knowledge-intensive services firms (KIS) depend on the skills and networks of employees, and tend to cluster in large-city regions. This raises the fundamental question of whether KIS 'learn through urban labour pools' in manners that have implications for innovation. To address it, a distinction is in this paper made between 'related variety' (RV) and 'unrelated variety' (URV) of work-life experiences collected by employees and combined in firms. The empirical analysis uses innovation survey and register data to demonstrate that higher levels of URV among staff in urban KIS inspire innovation activity, and increase the probability of innovation success. Outside cities, where KIS on average have more specialised knowledge bases, innovation responds negatively to URV and positively to RV. As a result, the sign, size and significance of urban-rural dividing lines in innovation propensities depend on whether firms have cultivated the skill profiles that are most conducive to innovation in their locations. Constraints faced specifically by KIS outside cities in this respect are identified and implications for policy drawn.
\end{abstract}

\section{Acknowledgements}

Work with this paper has benefitted from discussions with Ron Boschma and Ingvild Jøranli. It utilizes the methodology originally developed by Tore Sandven of NIFU with funding from the Research Council of Norway (DEMOSREG program, contract number 209769). The usual disclaimers apply.

Key words: Urban, services, related variety, unrelated variety, innovation 


\section{Introduction}

Structural change favours knowledge intensive services, which tend to concentrate in cities. This indicates dependence on local resource conditions that derive from diversity, density and connectivity (Glaeser et al., 1992; Henderson et al., 1995; Doloreux and Shearmur, 2012). Still, the question of whether, and if so how, firms in the industry (hereby denoted KIS) depend on urban resources for innovation has yet to be raised in the dedicated service research field (Gallouj and Weinstein, 1997; Witell et al., 2016) and remains debated in geography (cf. Doloreux and Shearmur, 2012; Doloreux and Shearmur, 2013), in spite of considerable attention to the unique spatial structure of the industry (cf. Tether et al., 2012; Wood, 2006; Doloreux et al., 2008; Doloreux and Shearmur, 2009; Doloreux and Shearmur, 2012).

Local demand and advantages of face-to-face interaction with clients and other partners has traditionally been considered important drivers of innovation in urban contexts (e.g. Isaksen, 2004; Wood, 2006; Doloreux and Shearmur, 2012). However, KIS operate also in markets for inputs that are employees with specialized knowledge (Niosi et al., 2012; von Nordenflycht, 2011). This knowledge is to a large extent acquired through experience (Jøranli, 2018; Arrow, 1962; Teece, 2003). Even though mobility flows are most intense at the local level, interactions between firms and the labour markets of their locations have received limited attention in the geography of KIS literature. Instead, this literature has provided ambiguous evidence on differences in business network configurations and innovation output propensities across regions (e.g. Doloreux and Shearmur, 2012; Doloreux and Shearmur, 2009; Herstad and Ebersberger, 2015) that suggest ' ...current explanatory approaches are inadequate' (Doloreux and Shearmur, 2012: 101).

The recent contribution by Östbring et al. (2018) is therefore notable, as it demonstrates how the composition of work-life experiences 'collected' by employees in the labour market influence the economic performances of Swedish services firms. By doing so, it echoes 'evolutionary economic geography' (EEG) that on a more general basis has investigated how the productivity performances of firms respond to mobility flows in regional contexts (e.g. Timmermans and Boschma, 2014; Boschma et al., 2009). This approach establishes a clear link between organizations and knowledge dynamics in their locations, and acknowledges firmlevel heterogeneity. However, the relationship between productivity and innovation is complex (e.g. Crepon et al., 1998) and resources that support the former might not benefit the latter (Aarstad et al., 2016). Moreover, intrinsic sector characteristics have only occasionally been 
considered by EEG (e.g. Caragliu et al., 2016; Firgo and Mayerhofer, 2017; Herstad, 2018a). Thus, the main objective of this paper is to address conceptually and empirically a fundamental question left open in research on the geography of KIS: Whether firms 'learn through urban labour pools' in manners that have implications for innovation.

\section{Conceptual framework and hypotheses}

KIS are distinguished from services firms more generally by the commonality with advanced manufacturing that is value creation through the integration of sophisticated skills and technology. Yet, whereas manufactured goods are physical manifestations of resources used in development and production, the characteristics and user value of services derive to a larger extent from what agents bring with them into 'services encounters' (Voorhees et al., 2017), i.e. interactions required for the service to be provided. Accordingly, such provision is fundamentally a behavioural act, and innovation a renewal of this behaviour that relies on the effort of many interacting agents (Tuominen and Toivonen, 2011; Engen and Magnusson, 2015). This means that the knowledge and networks of employees are basic building blocks for service provision and innovation (Keeble and Nachum, 2002; Love et al., 2011; Tether, 2003).

As individuals move through the labour market, they acquire skills (e.g. Timmermans and Boschma, 2014) and build informal networks (e.g. Eriksson and Lengyel, 2019) that reflect what they do and who they meet. Generally, the density and diversity of economic activities in large-city regions foster advancement of individual careers (e.g. Gordon et al., 2015), and lubricates matching of employee skills with employer needs (Duranton and Puga, 2004; Helsley and Strange, 1990). Accordingly, urban firms might capture particularly large learning effects from mobility flows (Eriksson and Rodríguez-Pose, 2017).

A first question that this raises is whether urban labour markets leave imprints on the knowledge bases of individual firms. To approach this, a distinction can be made between urbanization as 'related variety' and urbanization as 'unrelated variety' where the latter refer to the colocation in cities of private and public sector activities that are fundamentally different from each other in terms of core technologies, skills and markets served (e.g. Frenken et al., 2007). For regions, this gives rise to the 'portfolio effect' that is protection from sector-specific business cycle chocks (ibid). For urban workers, it opens up for career paths to transcend firm and sector 
boundaries. Finally, for firms, it allows adjustments of internal knowledge bases in response to changing external circumstances and holds open the opportunity to recruit specialised skills from entirely different industries: Insurance companies hire police detectives to monitor potential fraud, while ICT firms hire experienced teachers to develop educational software (Jøranli, 2018). Based on this, a first hypothesis can be formulated predicting that urban KIS combine experiences 'collected' by individuals through mobility between different - i.e. 'unrelated' - sectors:

H1: Urban location is positively associated with unrelated variety of work-life experiences (URV) among KIS employees

Previous research has suggested that the mere size of urban agglomerations give rise to withinindustry heterogeneity at the firm level (Eriksson and Lengyel, 2019; Timmermans and Boschma, 2014). Scale and density might also foster differentiation at the industry level, if so implying that labour market segments are created in cities that link firms in 'different-yetrelated' services sectors. Following Frenken et al (2007), this can be referred to as 'related variety'. At the regional level, related variety stimulates cross-fertilization between industries that is beneficial for industrial dynamics and growth (ibid). At the micro level, it allows individuals to develop and capitalize on specialised skills without narrowing down career opportunities, and provide firms with access to pools of labour with broad yet domain-relevant expertise. Thus, scale and density of KIS activity in cities might leave the imprint of 'related variety' on the experiences that are combined in firms:

H2: Urban location is positively associated with related variety of work-life experiences $(R V)$ among KIS employees

The next and here central question is whether variations in the type and amount of experience variety present in firms matter for innovation. Concerning URV, the 'cognitive resource diversity theory' developed in research on human resources (cf. Horwitz, 2005) proposes that broad employee experiences are supportive of innovation as they stimulate creativity, reduce the risk of lock-in and provide firms with the resources required to experiment with 'new combinations of knowledge' (Østergaard et al., 2011). In line with this, Cox (2001) argues that a diverse workforce allow firms to reach equally diverse marketplaces, while Firgo and Mayerhofer (2017) found a positive relationship between employment growth in services and 
unrelated variety at the regional level. Herstad \& Ebersberger (2015) proposes that exposure to the vibrant labour markets of large-city regions is positively associated with the breadth and geographical reach of collaboration networks maintained by KIS because diversity of experiences stimulate external opportunity search (Laursen and Salter, 2006) and strengthen absorptive capacity by endowing firms with broad 'prior related knowledge' (Cohen and Levinthal, 1990).

The contrasting 'similarity attraction paradigm' (Horwitz, 2005) argues that operations run smoother because communication is less complicated when employees have shared characteristics and backgrounds (McPherson et al., 2001). In KIS, communication challenges stemming from the nature of service provision as distributed and embedded 'in practice' (Dougherty, 2004; Engen and Magnusson, 2015) may limit the capacity of firms to capture and translate diverse human resources into innovation, i.e. change that is generalized (Toivonen and Tuominen, 2009) beyond ad hoc problem-solving in specific service encounters. Vermeulen and van der Aa (2005), suggests that project teams in services exhibit a lower capacity for crossdepartmental collaboration than project teams in manufacturing. Östbring et al (2018) found a negative effect of unrelated experiences on productivity in Swedish services, while Madsen et al (2003) used an international sample when finding firms in financial services responding to inflows of diverse expertise by retaining rather than adjusting established practices. In line with this, Herstad (2018a) found innovation in technology-intensive services responding positively only to inflows of expertise from closely related industries.

Idea generation and successful implementation might benefit from different processes and resources (Axtell et al., 2000; Levinthal and March, 1993), meaning that the two perspectives on variety can be seen as complementary rather than competing: Following Galinsky et al. (2015), URV might stimulate creativity and trigger experimentation as proposed by cognitive resource diversity theory; yet, the capacity to transform diverse ideas and insights into innovation as 'generalized change' might still be limited as proposed by the similarity attraction paradigm, or responsive only to experiences that are different-yet-related, as proposed by recent research on services (Östbring et al., 2018) and evolutionary economic geography more generally (e.g. Timmermans and Boschma, 2014; Boschma et al., 2009). To acknowledge this, a distinction is here made between the firm-level decision to engage in innovation activities, and output that is conditional on such activities being initiated. Following the argumentation above, two closely related hypotheses are formulated: 
H3a: Unrelated variety of work-life experiences is positively associated with innovation activity in KIS

H3b: Related variety of work-life experiences is positively associated with commercial output from innovation activities when conducted by KIS

There are three main reasons why these relationships could differ between locations. First, they may be more pronounced when firms operate in dynamic urban labour markets where ongoing matching improves the quality of employer-employee matches (Helsley and Strange, 1990; Glaeser, 1999). Second, internal variety (of collected experiences) and external variety (of information, markets and resources in large-city regions) may have complementary as well as substitute effects on innovation efforts and outcomes: Experiences collected by staff as predicted in Hypothesis 1 and 2 may increase the capacity of urban KIS to identify and exploit opportunities for innovation and supportive resources in the local environment, or function as a substitute for own development work (Herstad and Ebersberger, 2014) and instead facilitate imitation (Lee and Rodríguez-Pose, 2013). Third, innovation strategies tend to be different in peripheral regions, where firms build stronger internal capabilities and draw on non-local network linkages to compensate for less local resources support (cf. the litterature review by Eder, 2019; Meili and Shearmur, 2019; Shearmur and Doloreux, 2016). Accordingly, regional differences in the firm-level relationship between experience variety and innovation are to be expected:

H4: The relationships between collected employee experiences and innovation predicted in Hypotheses $\mathrm{H} 3 \mathrm{a}$ and $\mathrm{H} 3 \mathrm{~b}$ differ between urban and rural locations

\section{Data, variables and estimation strategy}

The analysis uses innovation data sampled by the governmental agency Statistics Norway in the Seventh round of the Pan-European Community Innovation Survey (CIS2010) that build on the definitions and guidelines of the' Oslo Manual' (OECD, 2005). In contrast to many other European countries, participation in the Norwegian surveys is compulsory for sampled firms. The result is comparatively large data sets, which are not plagued by non-response biases. The 
2010 survey provide information on innovation activities and outcomes during the reference period 2008-2010. Prior to release for research purposes, the data were thoroughly reviewed and validated by Statistics Norway. For the purpose here, the data have been merged with Linked employer-employee registers (LEED) covering the years 2004-2008. Knowledge intensive services are defined as described in Table A1 in the Appendix. To allow labour replacement and diversity to be captured as detailed below, only firms established prior to 2006 are included. This gives 1,424 observations.

\section{Innovation activity and outcomes}

Innovation activity is captured by the variable ACTIVE that takes on the value 1 if firms reported innovation-related expenditures, positive outcomes, abandoned activities during the reference period; or ongoing and not yet finalized projects (e.g. Herstad, 2018b). Innovation output is captured by the variable PRODUCT that takes on the value 1 if firms introduced a new or significantly improved product (good or service) onto the market. The choice of this indicator for innovation output is motivated by the importance of new products to growth in KIS (e.g. Bogliacino et al., 2013), and the less frequent occurrence in the data here of process innovations ${ }^{1}$ that tend to occur in tandem with the introduction of new products (cf. Table 1 ).

Table 1: Distribution of innovation output. Proportions of total $(N=1424)$ in parentheses

\begin{tabular}{llll}
\hline & PRODUCT $=\mathbf{0}$ & PRODUCT $=\mathbf{1}$ & $\mathbf{N}$ \\
PROCESS $=\mathbf{0}$ & $901(0.63)$ & $213(0.15)$ & $1114(0.78)$ \\
PROCESS $=\mathbf{1}$ & $77(0.05)$ & $233(0.16)$ & $310(0.22)$ \\
$\mathbf{N}$ & $978(0.68)$ & $446(0.31)$ & $1424(1)$ \\
\hline
\end{tabular}

\section{Experience variety \& labour replacement}

The main independent variables capture the composition of 'experience years' collected by firms' staff at the start of the three-year period for which innovation is reported. Based on LEED, matrixes have been generated for each firm that uses industry codes to classify the workplaces of employees present in the firm in 2008 during the five-year period that ended this year (cf. Table 2). Notably, the matrixes describe the collective dimensions that is how experiences of employees are related to each other using entropy measures computed in accordance with Jaquemin and Berry (1979) as detailed in the Appendix.

\footnotetext{
${ }^{1}$ New or significantly improved methods for production, storage and delivery of goods or services, including support functions such as sales, accounting and ICTs (OECD, 2005).
} 
Unrelated variety (URV) is the distribution of experience-years across two-digit main industry groups. Related variety (RV) is the weighted sum of distributions at the 3-digit level within 2digit main groups, where the weight is the proportion of all experience-years that each 2-digit group account for. This operationalisation of RV and URV is as applied by Frenken et al. (2007) to describe the composition of employment in regions. To illustrate, Table 2 gives an example of a firm that engages in data processing and storage services (63.110) with a staff that exhibit $\mathrm{URV}=0.83 \mathrm{URV}$ and $\mathrm{RV}=0.10$, i.e. somewhat below the full sample means of $U R V=0.97$ and RV=0.14 (Table A2 in the Appendix).

From the example, it is evident that stability of staff inherently reduces the experience variety hypothesized to influence innovation positively. This demands that the (hypothesized positive) effect of experience variety is isolated from (positive or negative) effects of labour replacement (e.g. Herstad et al., 2015). Therefore, the variable CHURN is used in the analysis to capture the overall intensity of firms' interactions with the external labour market as the proportion of employees present in 2006 replaced with new employees during the two-year period leading up to the start of the CIS reference period in 2008.

Table 2: Example of experience variety matrix (firm with 20 employees). Experience-years classified based on SN2007 (building on NACE rev. 2)

\begin{tabular}{|c|c|c|c|c|c|}
\hline \multicolumn{2}{|c|}{ Year of observation } & \multicolumn{4}{|c|}{ Sector of employment in prior years } \\
\hline Employee no & 2008 & 2007 & 2006 & 2005 & 2004 \\
\hline 1 & 63.110 & 09.101 & 09.101 & 09.101 & 09.101 \\
\hline 2 & 63.110 & 63.110 & 63.110 & 63.110 & 63.110 \\
\hline 3 & 63.110 & 63.110 & 62.020 & 62.020 & 62.020 \\
\hline 4 & 63.110 & 63.110 & 63.110 & 63.110 & 63.110 \\
\hline 5 & 63.110 & 63.110 & 63.110 & 63.110 & 63.110 \\
\hline 6 & 63.110 & 63.110 & unemployed & unemployed & unemployed \\
\hline 7 & 63.110 & 63.110 & 63.110 & 63.110 & 63.110 \\
\hline 8 & 63.110 & 63.110 & 63.110 & 62.020 & 62.020 \\
\hline 9 & 63.110 & 63.110 & 63.110 & 63.110 & 63.110 \\
\hline 10 & 63.110 & 63.110 & 63.110 & 63.110 & 63.110 \\
\hline 11 & 63.110 & 63.110 & 63.110 & 63.110 & 63.110 \\
\hline 12 & 63.110 & 63.110 & 63.110 & unemployed & unemployed \\
\hline 13 & 63.110 & 63.110 & 63.110 & 63.110 & 63.110 \\
\hline 14 & 63.110 & 63.110 & 63.110 & 63.110 & 63.110 \\
\hline 15 & 63.110 & 63.110 & 71.121 & 71.121 & 71.121 \\
\hline 16 & 63.110 & 71.122 & 71.122 & 71.122 & 71.122 \\
\hline 17 & 63.110 & 63.110 & 63.110 & 26.110 & 26.200 \\
\hline 18 & 63.110 & 63.110 & 63.110 & 63.110 & 63.110 \\
\hline 19 & 63.110 & 63.110 & 26.300 & 26.300 & 26.300 \\
\hline 20 & 63.110 & 63.110 & 63.110 & 63.110 & 63.110 \\
\hline \multicolumn{5}{|c|}{ Unrelated experience diversity (Entropy of distribution between 2-digit groups) } & 0.830069 \\
\hline \multicolumn{5}{|c|}{ + Related experience diversity (Weighted entropy of distribution within 2-digit groups) } & 0.100334 \\
\hline \multicolumn{5}{|c|}{$=$ Total experience diversity (Entropy of distribution between 5-digit groups } & 0.930403 \\
\hline
\end{tabular}

The analysis focus on the most recent experiences, i.e. those collected in the period 2004-2008. There are two reasons for this. First, going further back would force us to assume that distant 
experiences count equal to more recent ones, or demand that a depreciation rate is implemented (cf. Hall et al., 2010). Such rates have been used in research on accumulated R\&D (ibid) and mobility inflows (e.g. Herstad et al., 2015), but would here have to be set arbitrarily in the absence of conventions. Second, while diversity matrixes require consistent sector classifications, standards have changed and expanded particularly in the service domain. For the period considered, the data allow the previous SN2002 (building on NACE Rev. 1.1) to be harmonized with the current SN2007 (building on NACE Rev. 2).

\section{Location}

The variable URBAN takes on the value 1 for firms located in a large-city labour market regions. It reflects research using commuting patterns to developed (Jukvam, 2002) and update (Gundersen and Jukvam, 2013) a classification consisting of 161 Norwegian 'housing and labour market regions' that are ordered on a centrality scale from 5 (the Capital) through 4 (other large cities) to 1 (peripheral regions). The CIS is sampled at the enterprise level, and enterprises may consist of several establishments in different regions. To preserve observations, the option of relocating multi-establishment enterprises to the regions that accounted for the largest share of employment is chosen over the alternative of excluding such enterprises altogether (cf. section on multicollinearity and robustness).

\section{Control variables}

Location choices, accumulated experiences and innovation propensities differ between industry groups. Therefore, 14 dummy variables are included in all regressions as controls for the 152 digit SN2007 industry groups described in Table A1. Variety measured as entropy is influenced by the size of the firm, and may be related to age. The logs of firm age (AGE) and size (SIZE) are therefore included as controls. To isolate effects of education, EDUL captures the average education level of firms' employees in 2008. The emphasis put in antecedent KIS literature on learning through face-to-face interaction with local clients is acknowledged by the variable LOCMAR that takes on the value 1 if firms state that the local market is their most important. Finally, the variable 'R\&D' is included only in the estimation of innovation output (cf. estimation strategy below) to isolate effects of experience variety from effects of systematic 
research and development work as strictly defined in the CIS. It takes on the value 1 for firms that engaged in internal research and development activities during the reference period.

\section{Estimation strategy}

The analysis progresses through three stages. In the first stage, RV and URV are dependent variables estimated simultaneously using seemingly unrelated least square regressions (Zellner, 1962). The first model include a third equation that estimate the relationship between URBAN and labour replacement, while the second model consists of two equations that estimate RV and URV with control for labour replacement.

The second and third stage consists of a two-step sample selection model in the tradition of Heckman (1979) that reflect Hypothesis 3a and 3b by distinguishing determinants of innovation activity $($ ACTIVE $=1)$ from determinants of outcomes (PRODUCT $=1$ if ACTIVE $=1)$ (e.g. Herstad et al., 2015). In the selection stage, the binary dependent variable ACTIVE is estimated using probit regression models. Based on the model identified as best fit, the Mills ratio (MR) is computed that capture unobserved determinants of innovation activity (Greene, 2000). It is included as a control in the outcome stage where PRODUCT is estimated only for active firms (Heckman, 1979). This procedure demand at least one variable that strongly determines selection but not outcomes, i.e. an exclusion restriction as the variable(s) is not included the outcome stage (Certo et al., 2016; Greene, 2000). The use of CHURN and EDUL as exclusion restrictions is discussed in the section on multicollinearity and robustness.

As the explanatory variables in estimations of innovation are continuous, curvilinear relationships might be present that would give rise to biased linear estimates unless polynomial terms for RV and URV are included. Following Haans et al. (2016), this demands that interaction terms capturing both the base term for variety and the polynomial term are included when testing Hypothesis H4. Doing so highlights the distinction between the variable (i.e. RV or URV) and the multiple terms used to represent it (e.g. base, polynomial and two interaction terms). Because it is the significance of the variable in a given specification form that is of interest, supplementary Wald's tests evaluate joint significance (of all terms) and the results are used to ascertain what the appropriate model specifications for ACTIVE and PRODUCT are. 
In order to interpret the impact of exogenous variables in probit models, it is necessary to calculate marginal effects (Hoetker, 2007). Therefore, predicted probabilities of ACTIVE and PRODUCT have been estimated in a range that span from the approximate minimum values of variety through the mean and up to the cut-point value for the 95th percentile of each variety distribution, and their associated marginal effects computed. Values for URBAN are specified as either 0 or 1 , while effects of all other variables are held constant at their respective means. To allow straightforward computation, reporting and interpretation of marginal effects, entropy measures used in the regressions have been standardised, i.e. rescaled as standard deviations relative to the full sample mean set to 0 .

\section{Results}

\section{Stage 1: Imprints of urban location}

Table 3 describes the results of the first estimation stage reflecting Hypotheses 1 and 2. Model 1 demonstrate that urban firms on average have higher turnover of staff than their non-urban counterparts, and more diverse collected experiences among employees. Model 2 demonstrates that RV and URV are strongly associated with the labour replacement rate, yet, the estimates for URBAN remain significant after it is controlled for.

Table 3: Estimations of experience variety and churn. All firms $(N=1424)$.

\begin{tabular}{|c|c|c|c|c|c|}
\hline & \multicolumn{3}{|c|}{ Model 1} & \multicolumn{2}{|c|}{ Model 2} \\
\hline & CHURN & $\mathrm{RV}$ & URV & RV & URV \\
\hline & $\begin{array}{l}\text { Coeff } \\
(\mathrm{se})\end{array}$ & $\begin{array}{l}\text { Coeff } \\
(\mathrm{se})\end{array}$ & $\begin{array}{l}\text { Coeff } \\
(\mathrm{se})\end{array}$ & $\begin{array}{l}\text { Coeff } \\
\text { (se) }\end{array}$ & $\begin{array}{l}\text { Coeff } \\
\text { (se) }\end{array}$ \\
\hline \multirow[t]{2}{*}{ SIZE } & $0.017 * * *$ & $0.226 * * *$ & $0.202 * * *$ & $0.211 * * *$ & $0.175^{* * *}$ \\
\hline & $(0.003)$ & $(0.021)$ & $(0.021)$ & $(0.021)$ & $(0.020)$ \\
\hline \multirow{2}{*}{ AGE } & -0.004 & $-0.377 * * *$ & $-0.492 * * *$ & $-0.374 * * *$ & $-0.486 * * *$ \\
\hline & $(0.008)$ & $(0.047)$ & $(0.046)$ & $(0.047)$ & $(0.044)$ \\
\hline \multirow[t]{2}{*}{ LOCMAR } & 0.003 & -0.065 & $-0.202 * * *$ & -0.068 & $-0.206 * * *$ \\
\hline & $(0.008)$ & $(0.052)$ & $(0.050)$ & $(0.051)$ & $(0.049)$ \\
\hline \multirow[t]{2}{*}{ EDUL } & $-0.031 * * *$ & -0.006 & -0.041 & 0.023 & 0.010 \\
\hline & $(0.005)$ & $(0.030)$ & $(0.029)$ & $(0.030)$ & $(0.029)$ \\
\hline \multirow[t]{2}{*}{ URBAN } & $0.037 * * *$ & $0.217 * * *$ & $0.179 * * *$ & $0.183 * * *$ & $0.120 * *$ \\
\hline & $(0.009)$ & $(0.055)$ & $(0.054)$ & $(0.055)$ & $(0.052)$ \\
\hline \multirow[t]{2}{*}{ CHURN } & & & & $0.925 * * *$ & $1.615^{* * * *}$ \\
\hline & & & & $(0.161)$ & $(0.153)$ \\
\hline \multirow[t]{2}{*}{ Constant } & $0.307 * * *$ & 0.216 & $0.869 * * *$ & -0.068 & $0.374^{*}$ \\
\hline & $(0.036)$ & $(0.222)$ & $(0.216)$ & $(0.225)$ & $(0.214)$ \\
\hline Observations & 1,424 & 1,424 & 1,424 & 1,424 & 1,424 \\
\hline R-squared & 0.110 & 0.168 & 0.212 & 0.187 & 0.270 \\
\hline Chi2(sig) & $175.64 * * *$ & $287.99 * * *$ & $384.11 * * *$ & $327.57 * * *$ & $525.95 * * *$ \\
\hline
\end{tabular}


This is in line with expectations in the two hypotheses. Notably, local market orientation is associated with more focused internal knowledge bases, as the estimate is insignificant for RV and significantly negative for URV.

\section{Stage 2: Innovation activity}

Table 4 gives the baseline results from estimations of ACTIVE reflecting Hypotheses H3a and 4.The decision to engage in innovation activity is positively associated with size, and negatively associated with labour churn and a strong orientation towards the local market. In Model 3, a significantly positive estimate for URV is obtained that is in line with expectations in Hypothesis 3a. Interactions between URBAN and variety considered in Model suggest that the relationship between URV and ACTIVE is significantly stronger outside large-city regions, and thus in line with the expectations of Hypothesis 4. Moreover, Model 5 detect significant curvilinear effects of URV.

Table 4: Baseline estimations of innovation activity (ACTIVE $=1)$. All firms $(N=1424)$.

\begin{tabular}{|c|c|c|c|c|}
\hline & Model 3 & Model 4 & Model 5 & Model 6 \\
\hline & $\begin{array}{l}\text { Coeff } \\
(s e)\end{array}$ & $\begin{array}{l}\text { Coeff } \\
\text { (se) }\end{array}$ & $\begin{array}{l}\text { Coeff } \\
\text { (se) }\end{array}$ & $\begin{array}{l}\text { Coeff } \\
\text { (se) }\end{array}$ \\
\hline \multirow[t]{2}{*}{ SIZE } & $0.132 * * *$ & $0.132 * * *$ & $0.118 * * *$ & $0.125^{* * *}$ \\
\hline & $(0.033)$ & $(0.033)$ & $(0.034)$ & $(0.033)$ \\
\hline \multirow[t]{2}{*}{ AGE } & 0.016 & 0.017 & 0.011 & 0.014 \\
\hline & $(0.074)$ & $(0.074)$ & $(0.074)$ & $(0.074)$ \\
\hline \multirow[t]{2}{*}{ LOCMAR } & $-0.452 * * *$ & $-0.444 * * *$ & $-0.454 * * *$ & $-0.446^{* * *}$ \\
\hline & $(0.076)$ & $(0.076)$ & $(0.076)$ & $(0.076)$ \\
\hline \multirow[t]{2}{*}{ EDUL } & $0.309 * * *$ & $0.307 * * *$ & $0.294 * * *$ & $0.297 * * *$ \\
\hline & $(0.048)$ & $(0.048)$ & $(0.049)$ & $(0.048)$ \\
\hline \multirow[t]{2}{*}{ CHURN } & $-0.424 *$ & $-0.428 *$ & $-0.532 * *$ & $-0.495^{*}$ \\
\hline & $(0.257)$ & $(0.258)$ & $(0.263)$ & $(0.262)$ \\
\hline \multirow[t]{2}{*}{ URBAN } & $-0.171 * *$ & $-0.195 * *$ & $-0.167 * *$ & -0.136 \\
\hline & $(0.084)$ & $(0.085)$ & $(0.084)$ & $(0.106)$ \\
\hline \multirow[t]{2}{*}{ RV } & -0.064 & -0.005 & -0.020 & -0.056 \\
\hline & $(0.041)$ & $(0.078)$ & $(0.064)$ & $(0.041)$ \\
\hline \multirow[t]{2}{*}{ URV } & $0.185^{* * * *}$ & $0.301 * * *$ & $0.197 * * *$ & $0.315^{* * * *}$ \\
\hline & $(0.043)$ & $(0.075)$ & $(0.046)$ & $(0.073)$ \\
\hline \multicolumn{2}{|l|}{ RV*URBAN } & $\begin{array}{l}-0.075 \\
(0.090)\end{array}$ & & \\
\hline URV*URBAN & & $\begin{array}{l}-0.165^{*} \\
(0.087)\end{array}$ & & $\begin{array}{l}-0.154 * \\
(0.084)\end{array}$ \\
\hline $\mathrm{RV}^{\wedge} 2$ & & & $\begin{array}{l}-0.020 \\
(0.027)\end{array}$ & \\
\hline $\mathrm{URV}^{\wedge} 2$ & & & $\begin{array}{l}-0.068 * * \\
(0.031)\end{array}$ & $\begin{array}{l}-0.020 \\
(0.061)\end{array}$ \\
\hline $\mathrm{URV}^{\wedge} 2 * \mathrm{URBAN}$ & & & & $\begin{array}{l}-0.050 \\
(0.070)\end{array}$ \\
\hline Constant & $\begin{array}{l}-1.442 * * * \\
(0.351)\end{array}$ & $\begin{array}{l}-1.394 * * * \\
(0.353)\end{array}$ & $\begin{array}{l}-1.213 \text { *** } \\
(0.373)\end{array}$ & $\begin{array}{l}-1.304 * * * \\
(0.362)\end{array}$ \\
\hline \multicolumn{5}{|c|}{ Walds Chi2 tests of joint coefficient significance } \\
\hline All terms involving RV & n.a. & 2.93 & 2.39 & n.a. \\
\hline All terms involving URV & n.a. & $21.34 * * *$ & $19.97 * * *$ & $26.56^{* * * *}$ \\
\hline LR Chi2(df) & $326.82(22) * * *$ & $332.72(24) * * *$ & $332.16(24)^{* * *}$ & $335: 71(25)^{* * * *}$ \\
\hline Pseudo R2 & 0.166 & 0.169 & 0.169 & 0.172 \\
\hline
\end{tabular}


As terms capturing RV are neither individual nor jointly significant in any of the model specifications, the best fit is Model 6 that account for curvilinearity and interactions involving only URV.

Table 5 reports predicted probabilities for ACTIVE and marginal effects of URV computed on the basis for Model 6. The relationship is positive for KIS both inside and outside large-city regions. Yet, whereas marginal effects for urban firms loses significance around 0.4 SD above the mean, predicted probabilities continue to increase as URV increases in firms outside cities. As is evident from ME URBAN reported in the right-hand column, this gives rise to significant urban-rural dividing lines in innovation activity propensities at $0.4 \mathrm{SD}$ above the mean URV and upward.

Table 5: Predicted probabilities of innovation activity (ACTIVE =1) and marginal effects of URV and URBAN. Computed from Model 6. All other variables are held constant at their mean effect.

\begin{tabular}{|c|c|c|c|c|c|c|c|c|}
\hline \multirow{3}{*}{$\begin{array}{l}\text { URV } \\
-2\end{array}$} & \multicolumn{3}{|c|}{ URBAN $=1$} & \multicolumn{3}{|c|}{ URBAN $=0$} & \multicolumn{2}{|c|}{ ME URBAN } \\
\hline & $\mathrm{PP}$ & ME & SE & $\mathrm{PP}$ & $\mathrm{ME}$ & $\mathrm{SE}$ & $\mathrm{ME}$ & $\mathrm{SE}$ \\
\hline & 0.239 & 0.136 & $0.037 * * *$ & 0.247 & 0.124 & $0.062 * *$ & -0.008 & 0.091 \\
\hline-1.6 & 0.293 & 0.131 & $0.041 * * *$ & 0.299 & 0.131 & $0.062 * *$ & -0.006 & 0.068 \\
\hline-1.2 & 0.343 & 0.120 & $0.040 * * *$ & 0.352 & 0.134 & $0.056^{* *} *$ & -0.008 & 0.049 \\
\hline-0.8 & 0.388 & 0.104 & $0.034 * * *$ & 0.405 & 0.134 & $0.046^{* * * *}$ & -0.017 & 0.040 \\
\hline-0.4 & 0.426 & 0.085 & $0.027 * * *$ & 0.459 & 0.131 & $0.034 * * *$ & -0.032 & 0.040 \\
\hline 0 & 0.456 & 0.064 & $0.021 * * *$ & 0.510 & 0.125 & $0.029 * * *$ & -0.054 & 0.042 \\
\hline 0.4 & 0.477 & 0.042 & $0.021 * *$ & 0.559 & 0.118 & $0.035 * * *$ & -0.082 & $0.043 *$ \\
\hline 0.8 & 0.489 & 0.020 & 0.026 & 0.604 & 0.109 & $0.047 * *$ & -0.115 & $0.045^{*}$ \\
\hline 1.2 & 0.493 & -0.002 & 0.035 & 0.646 & 0.100 & $0.059 *$ & -0.153 & $0.053 * *$ \\
\hline 1.6 & 0.488 & -0.024 & 0.045 & 0.684 & 0.090 & 0.069 & -0.196 & $0.072 * *$ \\
\hline 2 & 0.473 & -0.046 & 0.055 & 0.718 & 0.080 & 0.076 & -0.244 & $0.099 * *$ \\
\hline
\end{tabular}

\section{Stage 3: Innovation outcomes}

Table 6 reports baseline results from estimations of PRODUCT that include only active firms when testing Hypothesis $3 \mathrm{~b}$ in light of Hypothesis 4. The importance of making the distinction between activity and outcome is illustrated by positive and strongly significant estimate for RV and a significantly negative interaction with URBAN. Thus, whereas RV is not associated with the initial decision to engage, it provides support for innovation success specifically among active firms located outside large-city regions. Conversely, the interaction between URBAN and URV is significantly positive, while the baseline estimate for URV is insignificant. When curvilinear effects are considered in Model 9, baseline and polynomial terms are neither individually nor jointly significant. Accordingly, the best fit is Model 7 that accounts for the significant interactions of RV and URV with URBAN that are supportive of Hypothesis 4 and 
means that the support for Hypothesis $3 b$ is conditional (on location outside a large-city region). The final Model 9 mirrors Model 7; however, CHURN and EDUL that were not significant in the prior estimations are here omitted as exclusion restrictions.

Table 6: Baseline estimations of product innovation (PRODUCT=1). Only innovation-active observations $(N=658)$

\begin{tabular}{|c|c|c|c|}
\hline & Model 7 & Model 8 & Model 9 \\
\hline & $\begin{array}{l}\text { Coeff } \\
\text { (se) }\end{array}$ & $\begin{array}{l}\text { Coeff } \\
\text { (se) }\end{array}$ & $\begin{array}{l}\text { Coeff } \\
\text { (se) }\end{array}$ \\
\hline SIZE & $\begin{array}{l}-0.177 * \\
(0.090)\end{array}$ & $\begin{array}{l}-0.072 \\
(0.084)\end{array}$ & $\begin{array}{l}-0.138 * * \\
(0.057)\end{array}$ \\
\hline AGE & $\begin{array}{l}0.072 \\
(0.118)\end{array}$ & $\begin{array}{l}0.092 \\
(0.117)\end{array}$ & $\begin{array}{l}0.082 \\
(0.117)\end{array}$ \\
\hline LOCMAR & $\begin{array}{l}-0.055 \\
(0.279)\end{array}$ & $\begin{array}{l}-0.447^{*} \\
(0.268)\end{array}$ & $\begin{array}{l}-0.186 \\
(0.160)\end{array}$ \\
\hline CHURN & $\begin{array}{l}0.531 \\
(0.450)\end{array}$ & $\begin{array}{l}0.035 \\
(0.469)\end{array}$ & \\
\hline EDUL & $\begin{array}{l}-0.078 \\
(0.191)\end{array}$ & $\begin{array}{l}0.196 \\
(0.179)\end{array}$ & \\
\hline $\mathrm{R} \& \mathrm{D}$ & $\begin{array}{l}0.387 \text { *** } \\
(0.128)\end{array}$ & $\begin{array}{l}0.399 * * * \\
(0.128)\end{array}$ & $\begin{array}{l}0.381 * * * \\
(0.128)\end{array}$ \\
\hline URBAN & $\begin{array}{l}0.182 \\
(0.150)\end{array}$ & $\begin{array}{l}0.079 \\
(0.151)\end{array}$ & $\begin{array}{l}0.150 \\
(0.121)\end{array}$ \\
\hline RV & $\begin{array}{l}0.280 * * \\
(0.130)\end{array}$ & $\begin{array}{l}0.034 \\
(0.100)\end{array}$ & $\begin{array}{l}0.266^{* * *} \\
(0.127)\end{array}$ \\
\hline URV & $\begin{array}{l}-0.283 \\
(0.205)\end{array}$ & $\begin{array}{l}0.159 \\
(0.131)\end{array}$ & $\begin{array}{l}-0.180 \\
(0.124)\end{array}$ \\
\hline RV*URBAN & $\begin{array}{l}-0.322 * * \\
(0.142)\end{array}$ & & $\begin{array}{l}-0.323 * * \\
(0.143)\end{array}$ \\
\hline URV*URBAN & $\begin{array}{l}0.378^{* * *} \\
(0.164)\end{array}$ & & $\begin{array}{l}0.321 * * \\
(0.135)\end{array}$ \\
\hline $\mathrm{RV}^{\wedge} 2$ & & $\begin{array}{l}-0.024 \\
(0.041)\end{array}$ & \\
\hline $\mathrm{URV}^{\wedge} 2$ & & $\begin{array}{l}-0.054 \\
(0.060)\end{array}$ & \\
\hline Constant & $\begin{array}{l}1.807 \\
(1.708)\end{array}$ & $\begin{array}{l}-0.670 \\
(1.547) \\
\end{array}$ & $\begin{array}{l}1.109 * * \\
(0.474)\end{array}$ \\
\hline \multicolumn{4}{|c|}{ Walds Chi2 tests of joint coefficient significance } \\
\hline All terms involving RV & $5.37 *$ & 0.034 & $5.08^{*}$ \\
\hline All terms involving URV & $6.82 * *$ & 1.52 & $7.01 * *$ \\
\hline LR Chi2(df) & $73.89(26) * * *$ & $66.19(26)^{* * *}$ & $72.49(24) * * *$ \\
\hline Pseudo R2 & 0.089 & 0.080 & 0.087 \\
\hline
\end{tabular}

Table 7 reports predicted probabilities of PRODUCT and marginal effects of RV and URV computed based on Model 9. Outside large-city regions, firms with URV at the mean (held constant) and low to moderate levels of RV (allowed to vary) exhibit significantly lower innovation propensities than their urban counterparts (cf. ME URBAN). Yet, the sign and significance of this difference changes as increases in RV outside cities are associated with strong increases in the probability of PRODUCT throughout the range of observed RV. Inside cities, the probability does not respond to RV. However, when RV is held constant at the mean and URV increases from 0.4 standard deviations below the mean and upwards, urban firms 
exhibit significant increases in the probability of PRODUCT that are paralleled by decreasing innovation propensities outside cities. This gives rise to significant urban-rural differences in predicted probabilities when firms with above-mean URV and mean RV (held constant) are compared.

Table 7: Predicted innovation outcome probabilities (PRODUCT =1) and marginal effects of RV, URV and URBAN. Computed from Model 9. All other variables are held constant at their mean effect.

\begin{tabular}{|c|c|c|c|c|c|c|c|c|c|}
\hline \multirow{3}{*}{$\mathrm{RV}$} & \multirow[b]{3}{*}{-0.8} & \multicolumn{3}{|c|}{ URBAN $=1$} & \multicolumn{3}{|c|}{ URBAN $=0$} & \multicolumn{2}{|c|}{ ME URBAN } \\
\hline & & PP & $\mathrm{ME}$ & SE & PP & ME & SE & $\mathrm{ME}$ & SE \\
\hline & & 0.730 & -0.015 & 0.024 & 0.553 & 0.106 & $0.051 * *$ & 0.178 & $0.060 * * *$ \\
\hline & -0.4 & 0.724 & -0.015 & 0.024 & 0.595 & 0.104 & $0.050 * *$ & 0.129 & $0.048 * * *$ \\
\hline & 0 & 0.718 & -0.015 & 0.025 & 0.636 & 0.101 & $0.047 * *$ & 0.082 & $0.044 * *$ \\
\hline & 0.4 & 0.712 & -0.016 & 0.025 & 0.675 & 0.097 & $0.043 * *$ & 0.037 & 0.048 \\
\hline & 0.8 & 0.706 & -0.016 & 0.026 & 0.713 & 0.091 & $0.038 * *$ & -0.007 & 0.058 \\
\hline & 1.2 & 0.699 & -0.016 & 0.026 & 0.748 & 0.086 & $0.031 * * *$ & -0.049 & 0.070 \\
\hline & 1.6 & 0.693 & -0.016 & 0.027 & 0.781 & 0.079 & $0.025 * * *$ & -0.088 & 0.081 \\
\hline & 2 & 0.686 & -0.016 & 0.027 & 0.812 & 0.072 & $0.018 * * *$ & -0.125 & 0.091 \\
\hline & 2.4 & 0.680 & -0.016 & 0.027 & 0.839 & 0.066 & $0.012 * * *$ & -0.159 & 0.101 \\
\hline & 2.8 & 0.673 & -0.016 & 0.028 & 0.864 & 0.059 & $0.007 * * *$ & -0.191 & $0.109 *$ \\
\hline URV & -2 & 0.616 & 0.049 & 0.031 & 0.796 & -0.061 & $0.022 * * *$ & -0.180 & $0.096 *$ \\
\hline & -1.6 & 0.635 & 0.049 & 0.030 & 0.771 & -0.065 & $0.027 * *$ & -0.135 & 0.084 \\
\hline & -1.2 & 0.654 & 0.048 & 0.030 & 0.744 & -0.069 & $0.032 * *$ & -0.089 & 0.071 \\
\hline & -0.8 & 0.673 & 0.047 & 0.029 & 0.715 & -0.073 & $0.037 * *$ & -0.042 & 0.059 \\
\hline & -0.4 & 0.692 & 0.046 & $0.027 *$ & 0.686 & -0.076 & $0.041 *$ & 0.006 & 0.049 \\
\hline & 0 & 0.710 & 0.044 & $0.026^{*}$ & 0.655 & -0.079 & $0.044 *$ & 0.055 & 0.044 \\
\hline & 0.4 & 0.727 & 0.043 & $0.024 *$ & 0.623 & -0.081 & $0.047 *$ & 0.105 & $0.046^{* *}$ \\
\hline & 0.8 & 0.744 & 0.042 & $0.023^{*}$ & 0.590 & -0.083 & $0.048 *$ & 0.154 & $0.056^{* * *}$ \\
\hline & 1.2 & 0.760 & 0.040 & $0.021 *$ & 0.556 & -0.085 & $0.049^{*}$ & 0.204 & $0.071 * * *$ \\
\hline & 1.6 & 0.776 & 0.039 & $0.019 * *$ & 0.522 & -0.085 & $0.049 *$ & 0.254 & $0.087 * * *$ \\
\hline & 2 & 0.791 & 0.037 & $0.017 * *$ & 0.488 & -0.085 & $0.047 *$ & 0.304 & $0.104 * * *$ \\
\hline
\end{tabular}

\section{Multicollinearity diagnostics and robustness tests}

In the selection stage (ACTIVE=1), the maximum variance inflation factor (VIF) is 3.75 and the condition number $(\mathrm{CN})$ is 27.07 (Model 6). The latter indicates that some multicollinearity is present, yet max VIF and CN are below the rule-of-thumb levels of 10 (e.g. Bogliacino and Cardona, 2014) and 30 (e.g. Salmerón et al., 2018) respectively that indicate serious concerns. In the outcome Model 7, a max VIF of 7.45 and a $\mathrm{CN}$ of 79.61 indicate multicollinearity. If MR is excluded, the results remain structurally consistent ${ }^{2}$, yet, a $\mathrm{CN}$ of 34.41 indicate that multicolinearity is still a concern. If instead EDUL and CHURN are removed as in Model 9, VIF and CN drops to 4.39 and 23.75 respectively. This does not indicate multicolinearity concerns, and underscores the importance of exclusion restrictions in sample selection models.

Supplementary tests for interactions between i) RV and URV with EDUL (cf. Östbring et al., 2018) and ii) URV and RV with R\&D only in the estimation of PRODUCT (reflecting the

\footnotetext{
${ }^{2}$ Evidence has been provided to the Journal in the review process
} 
literature on 'absorptive capacity', cf. Cohen and Levinthal (1990)) did not detect any significant effects.

The use of models with non-linear transformation of binary dependent variables (logit or probit) is a convention that the analysis here adheres to. Still, it has been argued that linear probability models are preferable as nonlinear transformations are susceptible to biases from unobserved heterogeneity (Mood, 2009). To investigate whether such biases might be present, the models identified as best fit for ACTIVE and PRODUCT have been re-estimated using the ordinary least square estimator with heteroscedasticity - robust standard errors. Baseline results, tests for joint significance and detailed marginal effects are fully consistent with those obtained from the probit estimations reported in the main text ${ }^{3}$.

To preserve observations, the analysis included multi-establishment enterprises. Yet, the relationship between internal variety, location and performance might be different in such enterprises compared to those that operate a single plant (Östbring et al., 2018; Herstad and Ebersberger, 2014). Re-estimations of the models for only single-establishment enterprises yield baseline results and marginal effects that are structurally consistent with those presented and discussed; however, significance is somewhat lower due to the lower number of observations ${ }^{4}$.

\section{Discussion and conclusion}

This paper addressed the fundamental question of whether KIS 'learn through urban labour pools' in manners that have implications for innovation. To do so, it distinguished between 'related variety' (RV) and 'unrelated variety' (URV) of work-life experiences collected by employees and combined in firms. Unconditional support for Hypotheses 1 that predicted a positive relationship between urban location and URV means that diverse career opportunities for people and recruitment channels for firms are reflected in the knowledge bases of KIS. At the same time, agglomeration of different-yet-related services in cities also leaves the imprint of higher RV, as predicted in Hypothesis 2. Thus, broad industry-specific experiences combined

\footnotetext{
${ }^{3}$ Cf. previous footnote.

${ }^{4}$ Cf. previous footnote.
} 
with diverse experiences from other employment domains characterizes urban KIS 'on average', the mirror image of which is more specialised knowledge bases outside cities.

Still, averages might conceal substantial firm-level heterogeneity. To capture how actual variations in RV and URV matter for innovation, the analysis distinguished between the decision to engage in development work and outcomes in the form of new product introductions. Both urban and rural firms respond as predicted in Hypothesis 3a, in that URV observed in 2008 is positively associated with innovation activity in the three-year period following thereafter. At the same time, the relationship is significantly stronger outside cities. This support for Hypothesis 4 on interaction effects between experience variety and location suggests that the less dense and diverse firms' surroundings are the more important is withinfirm variety to inspire innovation activity. Interaction effects where even more pronounced in the estimation of output from innovation activity if conducted: Whereas product innovation propensities increase with URV at moderate to high levels in urban KIS, URV significantly reduces innovation propensities among rural KIS through the entire range considered. Instead, innovation responds as predicted in Hypothesis $3 b$ positively to $\mathrm{RV}$, the effect of which 'in cities' is zero.

These results suggest, first, that URV is beneficial for innovation only when reflecting the learning opportunities provided to individuals in cities, and well matched within firms. In extension, and second, URV might provide KIS in cities with the search and absorptive capacity required to identify and capitalize on other local resources for innovation, e.g. local information flows. More fundamentally, and third, choices to locate, or remain and evolve, in certain types of regions demand organizational models and strategies adapted to local conditions. Over time, this may lead to different logics of organizational learning and innovation: Urban firms 'learnto-learn' through external labour pool. Firms outside cities, by contrast, might lean towards innovating based on stronger organizational capabilities developed over time (Shearmur and Doloreux, 2016; Meili and Shearmur, 2019). As this comes with the risk of lock-in to established practices, URV is important to challenge them. Still, actual learning benefits from inflows of new experiences are limited to those associated with RV that integrate smoothly (e.g. Herstad, 2018a).

Thus, the size, sign and significance of urban-rural dividing lines in innovation propensities are contingent; they depends on whether firms have cultivated the skill profiles that are most conducive to innovation in their respective types of locations. For urban KIS, this involves exploiting fully the local resources that are in abundant supply, i.e. URV. Rural KIS, by 
contrast, depend for innovation on related industry experiences, which might be scarce due to lower density of different-yet-related activity in their regions. Clustering is one way to overcome this limitation (cf. Eriksson et al., 2008; ). Yet, the strong preference currently revealed in favour of large cities (cf. Table A1) indicate that services clusters are unlikely to emerge and consolidate elsewhere unless local demand is particularly beneficial or support is provided by policy. In the absence of such support, rural locations may well become "places that don't matter' (Rodríguez-Pose, 2018) in the innovation-intensive services economy. Moreover, growth foremost in urban services where innovation thrive on 'hire-and-fire' firm strategies and individual job-hopping in labour markets might come with rising income inequality (e.g. Wessel, 2013), and polarisation between those who are able to keep pace with the demands of the labour market, and those who are not (Lundvall, 1996).

Beyond the use of Norwegian data only, there are notable limitations to our study that warrants attention. First, innovation activity tend to persist over time (Cefis and Orsenigo, 2001), meaning that skills that are valuable for innovation might be attracted to active firms. While the two-step procedure reduces the risk that this type of endogeneity biases the estimates for innovation outcomes (e.g. Certo et al., 2016), the results of the selection stage should not be over-interpreted. Second, differentiation within the heterogeneous category that is 'KIS' has not been considered beyond the inclusion of sector controls, as the size of the sample prohibit detailed analysis at the sub-sector level. This limitation could be overcome in future research by pooling of innovation data from different rounds. For the same reason, and third, a much more differentiated regional landscape than captured by the binary variable URBAN has not been done justice. Finally, the analysis has left open the question of whether RV and URV is reflected in the configuration of business networks (i.e. search effects of experience variety), and whether the learning benefits captured by firms depend on experience variety itself and on different knowledge management practices (i.e. absorptive capacity effects of variety).

Still, it has shed important new light on the question raised at the outset: Large-city regions allow KIS to 'learn through labour pools' in manners that have strong implications for innovation. Yet, while the knowledge bases of firms on average bear visible imprints of such locations, local KIS differ in terms of whether they exploit the opportunity provided to recruit and combine diverse experience-based knowledge into new 'service'. Moreover, firms that swim against the tide and locate outside cities might pursue other paths to innovation. Accordingly, there are different innovation models at play, and firm-level heterogeneity in the extent to which they are cultivated. Unless this is recognized in research on the geography of 
innovation, empirical ambiguity and conceptual debates 'pro vs. con urban' might overshadow the need for policies that work towards overcoming limitations on innovation-based development in services outside cities, and mitigate negative social consequences within them.

\section{Appendix}

\section{Computation of experience variety}

Each experience-year observed in the period 2004-2008 has been assigned a five-digit SN2007 industry code that capture the sector in which it was generated. If each firm has $n$ types of experience-years present, represented by the industry classes, and $\mathrm{Pi}$ is each 2-digit category's proportion of the total number of experience-years present within the firm, then the total entropy for each firm is given by Jacquemin \& Berry (1979:360) as:

$$
E_{T}=\sum_{i=1}^{n} P_{i} \ln \frac{1}{P_{i}}
$$

Sector codes are structured hierarchically as specialized sub-fields within main aggregate fields. If there are s main fields, and Ps is the proportion of experience-years accounted in each, then the distribution of experience-years across main sector classes is given by Jacquemin \& Berry (1979:361) as:

$$
E_{A}=\sum_{S=1}^{s} P_{S} \ln \frac{1}{P_{S}}
$$

Entropy within each sector class that is likewise given as:

$$
E_{w}=\sum_{i \in S} \frac{P_{i}}{P_{s}} \ln \frac{P_{s}}{P_{i}}
$$

The total entropy $E_{T}$ may be expressed in the following way (see Jacquemin and Berry, 1979:362 for details): 


$$
E_{T}=\sum_{i=1}^{n} P_{i} \ln \frac{1}{P_{i}}=\sum_{s=1}^{s} P_{S}\left(\sum_{i \in S} \frac{P_{i}}{P_{S}} \ln \frac{P_{s}}{P_{i}}\right)+\left(\sum_{s=1}^{s} P_{S} \ln \frac{1}{P_{S}}\right)
$$

Or simply:

$$
E_{t}=\sum_{s=1}^{s} P_{s}\left(E_{w}\right)+E_{A}
$$

Here, $E_{A}$ is the entropy of distribution across main industry classes that is URV, whereas the sum of $E_{w}$ weighted by $P_{s}$ is RV. Hence, the sum of URV and RV is the total experience variety of the firm, or $E_{T}$ as given in the first equation. 
Table A1: Description of sample.

\begin{tabular}{|c|c|c|c|c|c|c|}
\hline Section & 2-digit SN2007 & Industry & Share of sample & URBAN=1 & ACTIVE $=1$ & PRODUCT $=1$ \\
\hline \multirow[t]{6}{*}{$\mathrm{J}$} & 58 & Publishing of books, newspapers, journals, games and software & 0.156 & 0.662 & 0.581 & 0.477 \\
\hline & 59 & Motion pictures, video and television, sound recording and music publishing & 0.033 & 0.617 & 0.170 & 0.085 \\
\hline & 60 & Programming and broadcasting & 0.019 & 0.519 & 0.111 & 0.037 \\
\hline & 61 & Telecommunications & 0.050 & 0.746 & 0.493 & 0.366 \\
\hline & 62 & Computer programming, consultancy and related & 0.154 & 0.705 & 0.664 & 0.455 \\
\hline & 63 & Information services & 0.041 & 0.780 & 0.508 & 0.390 \\
\hline \multirow[t]{3}{*}{$\mathrm{K}$} & 64 & Financial services except insurance & 0.074 & 0.457 & 0.324 & 0.181 \\
\hline & 65 & Insurance except compulsory social security & 0.037 & 0.673 & 0.250 & 0.154 \\
\hline & 66 & Activities auxiliary to financial services and insurance & 0.051 & 0.822 & 0.205 & 0.123 \\
\hline \multirow[t]{4}{*}{$\mathrm{M}$} & 70 & Management consultancy & 0.040 & 0.667 & 0.386 & 0.316 \\
\hline & 71 & Architectural and engineering services, technical testing and analysis & 0.200 & 0.635 & 0.474 & 0.263 \\
\hline & 72 & Scientific research and development & 0.037 & 0.717 & 0.736 & 0.377 \\
\hline & 74 & Other scientific and technical activities & 0.032 & 0.733 & 0.600 & 0.467 \\
\hline \multirow[t]{3}{*}{$\mathrm{N}$} & 79 & Travel agency and tour operators & 0.044 & 0.468 & 0.210 & 0.161 \\
\hline & 82 & Office administrative and support activities & 0.032 & 0.804 & 0.196 & 0.130 \\
\hline & & All & $1(\mathrm{~N}=1424)$ & 0.662 & 0.462 & 0.313 \\
\hline
\end{tabular}

Table A2: Descriptive statistics \& bivariate correlations. $N=1424$.

\begin{tabular}{|c|c|c|c|c|c|c|c|c|c|c|c|c|c|c|c|c|c|}
\hline & & Mean & SD & Min & Max & 1 & 2 & 3 & 4 & 5 & 6 & 7 & 8 & 9 & 10 & 11 & 12 \\
\hline 3 & SIZE & 3.343 & 1.225 & 1.609 & 8.880 & 0.126 & 0.057 & 1 & & & & & & & & & \\
\hline 4 & AGE & 2.744 & 0.576 & 1.609 & 4.543 & -0.088 & -0.077 & 0.179 & 1 & & & & & & & & \\
\hline 6 & LOCMAR & 0.537 & 0.499 & 0 & 1 & -0.259 & -0.242 & -0.044 & 0.141 & -0.289 & 1 & & & & & & \\
\hline 7 & EDUL & 5.060 & 0.961 & 0 & 7.667 & 0.296 & 0.228 & 0.041 & -0.141 & 0.334 & -0.254 & 1 & & & & & \\
\hline 8 & CHURN & 0.204 & 0.157 & 0 & 1 & -0.063 & -0.031 & 0.103 & -0.014 & -0.101 & 0.018 & -0.178 & 1 & & & & \\
\hline 9 & URBAN & 0.662 & 0.473 & 0 & 1 & 0.060 & 0.076 & 0.170 & -0.127 & 0.074 & -0.166 & 0.256 & 0.090 & 1 & & & \\
\hline 12 & $\mathrm{RV}(\mathrm{std})$ & 0 & 1 & -0.938 & 5.037 & 0.053 & 0.039 & 0.265 & -0.200 & 0.048 & -0.093 & 0.078 & 0.172 & 0.195 & 1.000 & 0.352 & 1 \\
\hline 13 & URV(std) & 0 & 1 & -1.972 & 3.115 & 0.155 & 0.142 & 0.188 & -0.303 & 0.172 & -0.170 & 0.066 & 0.286 & 0.193 & 0.352 & 1.000 & 0.352 \\
\hline
\end{tabular}




\section{References}

Aarstad J, Kvitastein OA and Jakobsen S-E. (2016) Related and unrelated variety as regional drivers of enterprise productivity and innovation: A multilevel study. Research Policy 45: 844-856.

Arrow KJ. (1962) The Economic Implications of Learning by Doing. The Review of Economic Studies Ltd. 29: 155-173.

Axtell CM, Holman DJ, Unsworth KL, et al. (2000) Shopfloor innovation: Facilitating the suggestion and implementation of ideas. Journal of Occupational \& Organizational Psychology 73: 265385.

Bogliacino F and Cardona SG. (2014) Capabilities and investment in R\&D: An analysis on European data. Structural Change and Economic Dynamics 31: 101-111.

Bogliacino F, Lucchese M and Pianta M. (2013) Job creation in business services: Innovation, demand, and polarisation. Structural Change and Economic Dynamics 25: 95-109.

Boschma R, Eriksson R and Lindgren U. (2009) How does labour mobility affect the performance of plants? The importance of relatedness and geographical proximity. Journal of Economic Geography 9 (2): pp. 169-190.

Caragliu A, de Dominicis L and de Groot HLF. (2016) Both Marshall and Jacobs were Right! Economic Geography 92: 87-111.

Cefis E and Orsenigo L. (2001) The persistence of innovative activities: A cross-countries and crosssectors comparative analysis. Research Policy 30: 1139-1158.

Certo ST, Busenbark JR, Woo H-s, et al. (2016) Sample selection bias and Heckman models in strategic management research. 37: 2639-2657.

Cohen WM and Levinthal DA. (1990) Absorptive capacity - a new perspective on learning and innovation. Administrative Science Quarterly 35: 128-152.

Crepon B, Duguet E and Mairesse J. (1998) Research, innovation, and productivity: An econometric analysis at the firm level. Economics of Innovation and New Technology 7: 115-158.

Doloreux D, Amara N and Landry R. (2008) Mapping regional and sectoral characteristics of knowledge-intensive business services: Evidence from the Province of Quebec (Canada). Growth and Change 39: 464-496.

Doloreux D and Shearmur R. (2009) Place, Space and Distance: Towards a Geography of KnowledgeIntensive Business Services Innovation Industry and Innovation 16: 79-102.

Doloreux D and Shearmur R. (2012) Collaboration, information and the geography of innovation in knowledge intensive business services. Journal of Economic Geography 12: 79-105.

Doloreux D and Shearmur R. (2013) Exploring and comparing innovation patterns across different knowledge intensive business services. Economics of Innovation and New Technology 19: 605-625.

Dougherty D. (2004) Organizing Practices in Services: Capturing Practice-Based Knowledge for Innovation. Strategic Organization 2: 35-64.

Duranton G and Puga D. (2004) Micro-foundations of urban agglomeration economies. In: Henderson $V$ and Thiesse JF (eds) Handbook of Urban and Regional Economics. Amsterdam: North Holland.

Eder J. (2019) Innovation in the Periphery: A Critical Survey and Research Agenda. 42: 119-146.

Engen $M$ and Magnusson P. (2015) Exploring the role of front-line employees as innovators. The Service Industries Journal 35: 303-324.

Eriksson R, Lindgren $U$ and Malmberg G. (2008) Agglomeration mobility: effects of localisation, urbanisation, and scale on job changes. Environment and Planning A 40: 2419-2434.

Eriksson R and Rodríguez-Pose A. (2017) Job-related mobility and plant performance in Sweden. Geoforum 83: 39-49.

Eriksson RH and Lengyel B. (2019) Co-worker Networks and Agglomeration Externalities. Economic Geography 95: 65-89. 
Firgo M and Mayerhofer P. (2017) (Un)Related variety and employment growth at the sub-regional level. Papers in Regional Science.

Frenken K, Oort FV and Verburg T. (2007) Related Variety, Unrelated Variety and Regional Economic Growth. Regional Studies 41: 685-697.

Galinsky AD, Todd AR, Homan AC, et al. (2015) Maximizing the Gains and Minimizing the Pains of Diversity:A Policy Perspective. Perspectives on Psychological Science 10: 742-748.

Gallouj F and Weinstein O. (1997) Innovation in services. Research Policy 26: 537-556.

Glaeser E, Kallal H, Scheinkman J, et al. (1992) Growth in Cities. Journal of Political Economy 100: 1126-1152.

Glaeser EL. (1999) Learning in Cities. Journal of Urban Economics 46: 254-277.

Gordon I, Champion T and Coombes M. (2015) Urban Escalators and Interregional Elevators: The Difference that Location, Mobility, and Sectoral Specialisation Make to Occupational Progression. 47: 588-606.

Greene WH. (2000) Econometric Analysis (4 ed.), Upper Saddle River: Prentice Hall.

Gundersen F and Jukvam D. (2013) Inndelinger i senterstruktur, sentralitet og BA-regioner (Categorizations of centrality and labor market regions). NIBR Report 2013.

Haans RFJ, Pieters C and He Z-L. (2016) Thinking about U: Theorizing and testing U- and inverted Ushaped relationships in strategy research. Strategic Management Journal 37: 1177-1195.

Hall BH, Mairesse J and Mohnen P. (2010) Measuring the returns to R\&D. In: Hall BH and Rosenberg $\mathrm{N}$ (eds) Handbook of the Economics of Innovation. Elsevier, 1033-1082.

Heckman JJ. (1979) Sample selection bias as a specifcation error. Econometrica 47: 153-161.

Helsley RW and Strange WC. (1990) Matching and agglomeration economies in a system of cities. Regional Science and Urban Economics 20: 189-212.

Henderson V, Kuncoro A and Turner M. (1995) Industrial development in cities. Journal of Political Economy 103: 1067-1090.

Herstad S and Ebersberger B. (2014) Urban agglomerations, knowledge intensive services and innovation activity: Establishing the core connections. Entrepreneurship \& Regional Development 26: 211-233.

Herstad S and Ebersberger B. (2015) On the link between urban location and the involvement of knowledge intensive business services in collaboration networks. Regional Studies 49: 11601175.

Herstad S, Sandven T and Ebersberger B. (2015) Recruitment, knowledge integration and modes of innovation. Research Policy 44: 138-153.

Herstad SJ. (2018a) Beyond 'related variety': how inflows of skills shape innovativeness in different industries. European Planning Studies 26: 396-420.

Herstad SJ. (2018b) Innovation strategy choices in the urban economy. Urban Studies 55: 1185-1202.

Hoetker G. (2007) The use of logit and probit models in strategic management research: Critical issues. Strategic Management Journal 28: 331-343.

Horwitz SK. (2005) The compositional impact of team diversity on performance: Theoretical considerations. Human Resource Development Review 4: 219-245.

Isaksen A. (2004) Knowledge-based clusters and urban location: The clustering of software consultancy in Oslo. Urban Studies 41: 1157-1174.

Jaquemin AP and Berry CH. (1979) Entropy measures of diversification and corporate growth. Journal of Industrial Economics 27: 359-369.

Jukvam D. (2002) Defining labour market regions, Oslo: Norwegian Institute for Urban and Regional Research.

Jøranli I. (2018) Labour markets and the geography of firm learning. Department of Sociology and Human Geography. University of Oslo, Norway

Keeble D and Nachum L. (2002) Why do business service firms cluster? Small consultancies, clustering and decentralization in London and southern England. Transactions of the Institute of British Geographers 27: 67-90. 
Laursen $\mathrm{K}$ and Salter A. (2006) Open for innovation: The role of openness in explaining innovation performance among UK manufacturing firms. Strategic Management Journal 27 (2) 131-150.

Lee $\mathrm{N}$ and Rodríguez-Pose A. (2013) Original Innovation, Learnt Innovation and Cities: Evidence from UK SMEs. Urban Studies 50: 1742-1759.

Levinthal DA and March JG. (1993) The myopia of learning. Strategic Management Journal 14: 95112.

Love JH, Roper S and Bryson JR. (2011) Openness, knowledge, innovation and growth in UK business services. Research Policy 40: 1438-1452.

Lundvall BA. (1996) The social dimension of the learning economy. DRUID Working Papers 96.

McPherson M, Smith-Lovin L and Cook JM. (2001) Birds of a feather: Homophily in social networks. Annual Review of Sociology 27: 415-444.

Meili R and Shearmur R. (2019) Diverse diversities-Open innovation in small towns and rural areas. Growth and Change 0.

Mood C. (2009) Logistic Regression: Why We Cannot Do What We Think We Can Do, and What We Can Do About It. European Sociological Review 26: 67-82.

Niosi J, Athreye S and Tschang T. (2012) The global computer software sector. In: Malerba F and Nelson R (eds) Economic Development as a Learning Process: Variation across Sectoral Systems. Cheltenham: Edward Elgar.

OECD. (2005) Oslo Manual: Guidelines for collecting and interpreting innovation data, Paris: OECD \& Eurostat.

Rodríguez-Pose A. (2018) The revenge of the places that don't matter (and what to do about it). Cambridge Journal of Regions, Economy and Society 11: 189-209.

Salmerón R, García CB and García J. (2018) Variance Inflation Factor and Condition Number in multiple linear regression. Journal of Statistical Computation and Simulation 88: 2365-2384.

Shearmur R and Doloreux D. (2016) How open innovation processes vary between urban and remote environments: slow innovators, market-sourced information and frequency of interaction. Entrepreneurship \& Regional Development 28: 337-357.

Teece D. (2003) Expert talent and the design of professional service firms. Industrial and Corporate Change 12: 895-916.

Tether BS. (2003) The sources and aims of innovation in services: Variety between and within sectors. Economics of Innovation and New Technology 12: 481-505.

Tether BS, Quian CL and Mina A. (2012) Knowledge bases, places, spatial configurations and the performance of knowledge-intensive professional service firms. Journal of Economic Geography 12: 969-1001.

Timmermans B and Boschma R. (2014) The effect of intra- and inter-regional labour mobility on plant performance in Denmark: the significance of related labour inflows. Journal of Economic Geography 14: 289-311.

Toivonen M and Tuominen T. (2009) Emergence of innovations in services. The Service Industries Journal 29: 887 - 902.

Tuominen T and Toivonen M. (2011) Studying innovation and change activities in KIBS through the lens of innovative behaviour. International Journal of Innovation Management 15: 393-422.

Vermeulen P and van der Aa W. (2005) Organizing Innovation in Services. In: Tidd J and Hull FM (eds) Service Innovation. Organizational responses to technological opportunities \& market imperatives. London: Imperial College Press.

von Nordenflycht A. (2011) What is a professional service firm? Towards a theory and a taxonomy of knowledge-intensive firms. Academy of Management Review 35: 155-174.

Voorhees CM, Fombelle PW, Gregoire Y, et al. (2017) Service encounters, experiences and the customer journey: Defining the field and a call to expand our lens. Journal of Business Research 79: 269-280.

Wessel T. (2013) Economic Change and Rising Income Inequality in the Oslo Region: The Importance of Knowledge-Intensive Business Services. Regional Studies 47: 1082-1094. 
Witell L, Snyder H, Gustafsson A, et al. (2016) Defining service innovation: A review and synthesis. Journal of Business Research 69: 2863-2872.

Wood P. (2006) Urban development and knowledge-intensive business services: Too many unanswered questions? Growth and Change 37: 335-361.

Zellner A. (1962) An efficient meothod for estimating seemingly unrelated regressions and tests for aggregation bias. Journal of the American Statistical Association 57: 348-368.

Östbring L, Eriksson R and Lindgren U. (2018) Relatedness through experience: On the importance of collected worker experiences for plant performance. Papers in Regional Science 97: 501-518.

$\varnothing$ stergaard CR, Timmermans B and Kristinsson K. (2011) Does a different view create something new? The effect of employee diversity on innovation. Research Policy 40: 500-509. 